\title{
Recent advances in the development of breast cancer vaccines
}

\author{
This article was published in the following Dove Press journal: \\ Breast Cancer: Targets and Therapy \\ 14 October 2014 \\ Number of times this article has been viewed
}

\author{
Andrea Milani' \\ Dario Sangiolo' \\ Massimo Aglietta ${ }^{1,2}$ \\ Giorgio Valabrega ${ }^{1,2}$ \\ 'Department of Oncology, University \\ of Torino, Torino, Italy; ${ }^{2}$ FPO, Candiolo \\ Cancer Institute, IRCCS, Torino, Italy
}

Correspondence: Giorgio Valabrega Instituto di Candiolo, Fondazione del Piemonte per l'Oncologia, IRCCS, SP I42, Km 3.9510060 Candiolo, Torino, Italy

Tel +39 0l I 9933283

Fax +39 0119933299

Email giorgio.valabrega@ircc.it
Abstract: The manipulation of the immune system through the administration of a vaccine to direct an effective and long-lasting immune response against breast cancer (BC) cells is an attractive strategy. Vaccines would have several theoretical advantages over standard therapies, including low toxicities, high specificity, and long-lasting efficacy due to the establishment of immunological memory. However, $\mathrm{BC}$ vaccines have failed to demonstrate meaningful results in clinical trials so far. This reflects the intrinsic difficulty in breaking the complex immuneescaping mechanisms developed by cancer cells. New vaccines should be able to elicit complex immunologic response involving multiple immune effectors such as cytotoxic and antibodysecreting B cells, innate immunity effectors, and memory cells. Moreover, especially in patients with large tumor burdens and metastatic disease, combining vaccines with other strategies, such as systemic $\mathrm{BC}$ therapies, passive immunotherapy, or immunomodulatory agents, could increase the effectiveness of each approach. Here, we review recent advances in $\mathrm{BC}$ vaccines, focusing on suitable targets and innovative strategies. We report results of most recent trials investigating active immunotherapy in $\mathrm{BC}$ and provide possible future perspectives in this field of research. Keywords: breast cancer, cancer vaccines, cancer immunology, HER2, MUC-1, hTERT

\section{Introduction}

Recently, advances in early diagnosis and more effective treatments have reduced the mortality rate due to breast cancer $(\mathrm{BC}) .{ }^{1}$ However, despite this progress, $\mathrm{BC}$ remains a leading cause of death in the female population worldwide. ${ }^{2}$ In this scenario, manipulating the immune system to direct an effective and long-term immune response against $\mathrm{BC}$ cells through the administration of a vaccine is an attractive strategy. Tumor vaccination would have several theoretical advantages over standard therapies. First, the ideal tumor vaccine would induce potent and durable immune reactions against a broad spectrum of tumor antigens. It could be easily administered and manufactured, with modest side effects typical of conventional chemotherapies. Moreover, it would prevent further tumor recurrences, due to the establishment of persistent immune memory. At present, however, active immunotherapeutic strategies against cancer have failed to fulfill the above expectations in clinical trials. ${ }^{3}$ This reflects the intrinsic difficulty in finding optimal targets for a cancer vaccine, the most effective type of vaccination, route of administration, and the most immunologically favorable setting of disease (eg, low tumor burden, not heavily pretreated patients). Most importantly, it reflects the difficulty in breaking the complex immune-escaping mechanisms developed by cancer cells. ${ }^{4}$ The aim of this review is to summarize recent advances in BC active 
immunotherapy, to address recent results from clinical trials, and to provide possible future perspectives in this field of research.

\section{Targets and strategies of BC vaccines}

It has been well established that the immune system plays a role in controlling tumor growth, and adaptive immunity is the main mediator of "spontaneous" regression of certain types of cancers. ${ }^{5,6}$ The immune system has the ability to recognize several types of antigens expressed on tumor cell surfaces, namely the tumor-associated antigens (TAAs). ${ }^{7}$ TAAs are presented to immune system effectors such as T-cells by the tumor itself, through the major histocompatibility complex (MHC) or, more likely, by antigen presenting cells (APCs), in particular macrophages and dendritic cells (DCs). ${ }^{7}$ These cells are essential in processing antigens into immunogenic peptides and presenting them to naive T-cells through the MHC complex. Through a complex and regulated system of co-activator and inhibitory molecules expressed on the cell surface, these cells play an essential role in priming $\mathrm{T}$ lymphocytes and activating an immunogenic response against specific targets. ${ }^{8}$ The presence of tumorinfiltrating lymphocytes has been correlated with better prognosis in several types of cancers. ${ }^{9,10}$ However, tumor cells often develop the ability to circumvent the surveillance of the immune system. ${ }^{11}$ In the tumor microenvironment, molecules such as vascular endothelial growth factor, transforming growth factor (TGF)- $\beta$, and interleukins are abundant and both actively downregulate the immune function and promote tumor progression, invasion, and metastasis. ${ }^{12}$ In addition, tumor cells can directly downregulate T-cell function through expression of transmembrane inhibitory molecules such as FasL or B7-H1/PD-L1 or, indirectly, by promoting functionally suppressive CD4+FoxP3+ T lymphocyte (TReg) function. ${ }^{13,14}$ Finally, cancer cells can modulate expression or mask TAAs, reducing their availability and presentation to immune effectors. ${ }^{15}$ All these mechanisms can therefore lead to altered DC and T-cell function, and, as final result, to impaired immune response against tumor cells. Immune-escaping mechanisms are particularly active in epithelial cancers such as BC. ${ }^{16}$ However, some degree of immune response against TAAs can be demonstrated in BC patients. ${ }^{17-19}$ This has prompted researchers to develop active immunotherapies to therapeutically amplify these weak responses against known immunogenic BC antigens. In fact, the aim of an effective therapeutic vaccine is to break peripheral tolerance and activate low-affinity T-cells that were not eliminated during selection in thymus. ${ }^{20}$ A number of breast TAAs have been recognized and described so far (Table 1). Among them, human epithelial growth factor receptor 2 (HER2), carbohydrate antigens, telomerase reverse transcriptase (hTERT), and mucin-1 (MUC-1) have received the greatest attention for vaccine formulations ${ }^{7}$ and have been tested in clinical trials. In order to produce an effective vaccine, an antigen or a pool of antigens (as for whole-tumor-cell vaccines) should be delivered through an appropriate formulation. Activation of the immune system could be enhanced by including adjuvant compounds, and appropriate monitoring techniques should be prompted to assess the immunologic response. ${ }^{21}$ Recently, new technologies such as the use of nanoparticles and liposome formulations, which may improve efficacy of vaccines have received great attention, and preclinical studies with interesting results have been published. ${ }^{22-24}$ Indeed, various vaccine formulations have been tested so far, but none of these was shown to be superior in all situations. Distinct vaccination platforms engage different aspects of the antitumor immune response and each has its own pros and cons, as briefly summarized in Table 2.

\section{Peptide-based vaccination}

Peptide-based vaccines aim at inducing immune responses (including antibodies, cytotoxic T lymphocytes [CTLs], and helper T-cells) using antigenic epitopes derived from TAAs.

Table I Main breast cancer TAAs

\begin{tabular}{|c|c|}
\hline Target & Description \\
\hline $\begin{array}{l}\text { Carcinoembryonic } \\
\text { antigen }\end{array}$ & $\begin{array}{l}\text { Glycoprotein involved in cell adhesion, } \\
\text { normally expressed during fetal development }\end{array}$ \\
\hline $\begin{array}{l}\text { Human epithelial } \\
\text { growth factor }\end{array}$ & $\begin{array}{l}\text { Growth factor receptor belonging to human } \\
\text { epithelial growth factor receptor family }\end{array}$ \\
\hline receptor 2 & $\begin{array}{l}\text { Overexpressed in } 20 \%-30 \% \text { of breast cancer } \\
\text { cells, correlates with adverse prognosis }\end{array}$ \\
\hline MUC-I & $\begin{array}{l}\text { Membrane glycoprotein involved in } \\
\text { immunologic and cell signaling functions } \\
\text { Overexpressed in } 70 \% \text { of breast cancers }\end{array}$ \\
\hline hTERT & $\begin{array}{l}\text { Component of the telomerase complex, } \\
\text { a ribonucleoprotein that maintain chromosome } \\
\text { integrity during cell proliferation and division }\end{array}$ \\
\hline p53 & $\begin{array}{l}\text { Tumor suppressor protein, involved in cell } \\
\text { cycle regulation and DNA damage repair } \\
\text { Mutated in } 20 \% \text { of breast cancers }\end{array}$ \\
\hline Mammaglobin-A & $\begin{array}{l}\text { Glycoprotein overexpressed in } 80 \% \\
\text { of metastatic breast cancers }\end{array}$ \\
\hline $\begin{array}{l}\text { Cancer testis antigens } \\
\text { (NY-eso-I, MAGE, } \\
\text { BAGE, and GAGE) }\end{array}$ & $\begin{array}{l}\text { Proteins expressed in normal germ cells of the } \\
\text { testis and embryonic ovaries and in certain } \\
\text { types of cancer }\end{array}$ \\
\hline
\end{tabular}

Abbreviations: TAAs, tumor-associated antigens; hTERT, telomerase reverse transcriptase; MUC-I, mucin-I. 
Table 2 Current vaccine platforms

\begin{tabular}{|c|c|c|}
\hline Vaccine platform & Strengths & Possible limitations \\
\hline \multirow[t]{6}{*}{ Peptide-based vaccines } & Easily produced and delivered & Able to elicit mainly one compartment of immunological \\
\hline & Low toxicities & response (cytotoxic or humoral) \\
\hline & Easy to monitor immunologic response & Require boosts inoculation to maintain immunological memory \\
\hline & & HLA-restricted \\
\hline & & Require suitable adjuvant \\
\hline & & Response restricted to one or few epitopes \\
\hline \multirow[t]{3}{*}{ DC-based vaccines } & Not HLA restricted & Technically challenging \\
\hline & Capable to elicit immunological memory, & Requires expansion, maturation, and activation of DCs \\
\hline & humoral and cytotoxic response & \\
\hline \multirow[t]{3}{*}{ DNA-based vaccines } & Can be produced on larger scales & Risk of toxicities \\
\hline & Can elicit both humoral and cytotoxic & Low efficiency of naked DNA or plasmids \\
\hline & compartments & Difficulties in finding suitable vectors \\
\hline \multirow[t]{3}{*}{ Whole cell-based vaccines } & Can elicit a response against broad & Difficult to monitor response \\
\hline & spectrum of antigens & Risk of toxicities and autoimmunity \\
\hline & Not HLA-restricted & Requires cell manipulation to be immunogenic \\
\hline
\end{tabular}

Abbreviations: HLA, human leukocyte antigen; DC, dendritic cell.

Many of the first cancer vaccine strategies focused on inducing tumor-specific CD8+ cells with MHC class I restricted short peptides. ${ }^{25-27}$ It is now clear that these CD8+ T-cell responses are typically weak and short-lived. ${ }^{25,28}$ Further studies have clarified that triggering the CD4+ T-cell response is critical for maximizing tumor immunity, as it both optimizes the CD8+ T-cell response and supports the humoral antitumor immune response. ${ }^{29}$ Thus, researchers have focused on studying peptide-based vaccines that are able to trigger both $\mathrm{CD} 4+$ and $\mathrm{CD} 8+$ responses, using longer peptides or mixtures of epitopes. ${ }^{30}$ Peptide vaccines have several potential advantages, which include easy manufacturing, easily evaluable immunological response, and low expected toxicities. These advantages have made the peptide-based vaccination widely studied and employed in clinical trials. However, this strategy presents some objective limitations. First, to be effective, peptide vaccines often require co-administration of an immunological adjuvant. Adjuvants play an important role in favoring recruitment and efficient stimulation of immune effectors. Identification of an even more efficient adjuvant for a given vaccine is crucial for the effectiveness of the formulation and has been the object of intense research. Second, most of the peptide-based vaccines tested are restricted to HLA-A2. This limits the number of potentially benefiting patients. Third, although easily monitored, immune response is directed against one or a few epitopes, possibly reducing the effectiveness of response and favoring mechanisms of immune escape. Finally, we should consider populationand patient-specific variability in antigen processing and presentation, which could affect the effectiveness of such a strategy. ${ }^{31}$

\section{DNA-based vaccination}

The principle of this approach is based on the assumption that the DNA encoding for a given TAA can be taken by APCs, translated into protein, and finally processed for presentation. DNA can be delivered naked or complexed with other molecules. Frequently, the most used vectors are viruses that are able to efficiently transfect target cells..$^{32,33}$ Recently, new technologies such as nanoparticles and liposome preparations have been successfully employed to deliver DNA vaccines. ${ }^{34-36} \mathrm{~A}$ large body of evidence supports the idea that stimulating a coordinated immune response, involving cellular, humoral, and innate immune effectors (natural killer cells and macrophages), most effectively mediates tumor rejection. ${ }^{37,38}$ DNA vaccines, because of their unique mechanisms of action, could stimulate a more "physiologic" immune response against antigens and could be produced on a larger scale. However, finding an effective vector can be challenging.

\section{Dendritic cells-based vaccination}

DCs are the most important APCs. They naturally express high levels of MHC molecules, co-stimulatory proteins, and cytokines. ${ }^{39,40}$ Autologous DCs can be modified by fusion with cancer cells by pulsing with peptides or by transfection to express tumor antigens. ${ }^{41} \mathrm{DC}$ vaccination represents one of the most intriguing platforms in cancer vaccines. In fact, DCs are able to stimulate both class I and class II responses and can be further modified in order to co-express co-stimulatory molecules, and responses can be directed against multiple targets. This type of platform has been successfully employed and approved for clinical use in castration-resistant prostate cancer. ${ }^{42,43}$ However, this 
vaccine platform remains technically challenging due to the uncertainty related to the optimal route of administration and expansion, maturation, and/or activation of DC cells, which is not easily achievable ex vivo and, as a result, this limits larger scale manufacturing.

\section{Whole cells-based vaccination}

Another potential approach is immunizing the patient with whole tumor cells, derived from the patient herself (autologous) or from cell-line cultures (allogeneic). These vaccines have been shown to induce antigen-specific T-cell responses. However, more frequently, tumor cells act as antigenic pool for in vivo or ex vivo APCs presentation. To enhance immunological response, tumor cells can be genetically modified to express co-stimulatory molecules or cytokines. ${ }^{44}$ Theoretical advantages of such approach comprise providing a pool of tumor antigens, generating immune responses to more than one antigen, and thereby possibly overcoming the tumor antigen loss. ${ }^{45}$ Moreover, this could lead to a more "complex" response, involving both CD4+ and CD8+ T-cells, against different antigens. Potential drawbacks may be the triggering of autoimmunity and difficulties in monitoring the consequent immunologic response that may be directed against unknown TAAs. ${ }^{46}$

\section{Anti-HER2 vaccines}

HER2 is a protein receptor with tyrosine kinase activity belonging to the human epidermal growth factor receptor family overexpressed in $25 \%-30 \%$ of BC. ${ }^{47}$ HER 2 is effectively targeted by a number of new-generation therapies, such as the monoclonal antibodies trastuzumab, pertuzumab, or T-DM1, ${ }^{48-50}$ and small tyrosine kinase inhibitors such as Lapatinib, Neratinib, and Afatinib. ${ }^{51-53}$ HER2 is a suitable target for BC vaccines, and several investigations have shown that some patients develop spontaneous anti-HER2-specific immunity with high levels of both cellular and humoral response. ${ }^{17,54}$

The largest body of data resulting from anti-HER2 vaccinations derives from clinical trials employing peptide-based vaccines in different clinical settings. The most studied HER2-derived peptide in clinical trials is E75 (HER2 amino acids [aa] 369-377) derived from the extracellular domain of HER 2 and characterized by HLA-A2 restriction. ${ }^{55}$ In the initial studies, E75 was demonstrated to be safe and capable of inducing peptide-specific CD8+ response. The majority of patients enrolled in these pivotal studies had breast or ovarian cancer and were vaccinated with increasing doses of vaccine administered monthly, with up to six immunizations. ${ }^{17,25,26,56,57}$ In a retrospective analysis aimed at evaluating long-term outcome of BC patients enrolled in these early trials, it was shown that 21 out of $52(40 \%)$ identified patients were alive at the time of analysis (median follow-up [FU] of 112 months). ${ }^{58}$ Six out of eight $(75 \%)$ evaluable patients had persistent T-cell immunity versus immunizing HER2 peptides. Moreover, seven out of eight evaluable patients (88\%) developed T-cell-specific immunity against HER2 epitopes other than the one used for immunization, likely due to epitope spreading. These data showed that E75 was able to induce effective and long-lasting immunologic responses. Given the encouraging results, E75 was tested in two larger Phase II clinical trials in an adjuvant setting. ${ }^{59}$ A total of 195 women with HER2 positive (with score $\geq 1$ by immunohistochemistry) were included (100 lymph-node positive, 95 lymph-node negative) after completion of a standard course of surgery, chemotherapy, and radiotherapy. ${ }^{60}$ The final results of this study have been very recently reported. ${ }^{61}$ The vaccine was administered with granulocyte-macrophage colony-stimulating factor (GM-CSF) for up to six immunizations, and $49 \%$ of patients received booster inoculations. At 5 years, the disease-free survival (DFS) rate for vaccinated patients was $89.7 \%$ versus $80.2 \%$ for controls $(P=0.08) .{ }^{62}$ Although not statistically significant, vaccination was associated with a $48 \%$ reduction of relative risk of recurrence. Interestingly, among the node-positive population, benefits of vaccination were shown to be larger. In fact, the 24-month DFS rate was $90.2 \%$ for vaccinated patients and $79.1 \%$ for controls ( $P=0.13$ ), with a relative reduction of risk for recurrence of $53 \%$. Interestingly, patients expressing low levels of HER2 (immunohistochemistry 1 or 2+) had more robust immunologic response, ${ }^{63}$ and in this population the DFS rate was improved at 5 years of $F U,{ }^{64}$ with the DFS rate of $88.1 \%$ in vaccinated patients versus $77.5 \%$ in controls $(P=0.16)$. In contrast, in patients whose tumors overexpressed HER2, the DFS rate was $90.3 \%$ for vaccinated patients versus $83.3 \%$ for controls ( $P=0.44$ ). Of 30 vaccinated patients who had HER2-overexpressing tumors, only 12 patients received trastuzumab before vaccination, and none of these patients had recurrences. Because of the trial design, not all patients received the vaccine dose that was subsequently determined to be optimal. Moreover, a booster inoculation was administered in 53 patients (49\%). Intriguingly, among the patients who received booster inoculations the DFS rate at 5 years was $95.2 \%$ ( $P=0.11$ vs controls $)$.

AE37 is an HER2 (aa 776-779)-derived peptide modified with a "li-Key" motif in order to elicit a combined CD4+ T- and CD8+ T-cell response. ${ }^{28}$ This vaccine formulation was tested 
at three different doses with or without GM-CSF in 15 patients with node-negative $\mathrm{BC}$, in remission after standard therapy. Intriguingly, without adjuvants, AE37 was able to effectively elicit a specific combined response. ${ }^{65-67}$

Another HER2-derived peptide tested in clinical trials is GP2. This is a nine-aa, HLA-A2-restricted peptide derived from the transmembrane domain of HER2 (aa 654-662), with a lower affinity to HLA-A2 ${ }^{68}$ Preliminary results of a Phase II trial of the GP2 vaccine with GM-CSF were recently presented. ${ }^{69}$ In this trial, 172 HLA-A2-positive newly diagnosed women with node-positive or high-risk node-negative disease after standard therapy were enrolled. GP2 was shown to be able to elicit strong immunologic response in the vaccinated group, and, although not statistically significant, the immune response correlated with a $>50 \%$ reduction in $\mathrm{BC}$ recurrences ( $4.3 \%$ vs $11.6 \%$ in the vaccine and control group, respectively; $P=0.41)$.

Results of the clinical trials of anti-HER2 vaccines, using different types of platforms, are summarized in Table $3 .^{70-73}$

\section{Anti-MUC-I and anti-CEA vaccines}

MUC-1 is a membrane glycoprotein expressed by many types of epithelial cells, including breast, lung, and the gastrointestinal tract. ${ }^{74}$ In cancer cells, it is overexpressed and aberrantly glycosylated, and involved in cell-to-cell and cell-to-matrix adhesion, in signal transduction, and in modulation of the immune system. Nearly $70 \%$ of cancers overexpress MUC-1. ${ }^{74,75}$ It has been demonstrated that MUC-1 can be immunogenic and could be a suitable target for cancer immunotherapy. ${ }^{76-78}$
A series of pilot studies using anti-unglycosylated MUC-1 peptide-based vaccination were undertaken, with conflicting results. $^{79-83}$ Further studies showed that directing immunologic response against glycosylated form of MUC-1 could translate into stronger humoral responses. An anti-MUC-1 vaccination conjugated with keyhole limpet hemocyanin (KLH) was shown to elicit strong humoral response and to be safe. ${ }^{84-86}$ Based on these results, Miles et al conducted a Phase III trial in 1,028 women with metastatic BC who had previously received chemotherapy and had had either a complete or a partial response, or no disease progression. ${ }^{86}$ All women received T-Reg-depleting doses of cyclophosphamide $\left(300 \mathrm{mg} / \mathrm{m}^{2}\right) 3$ days before vaccine injection. Although the treatment was well tolerated and able to induce strong humoral response, no DFS or overall survival (OS) benefit emerged. ${ }^{3}$ However, in patients treated with concomitant hormone therapy (34\%), a trend toward improved time to progression and OS was observed. This observation suggests that combined therapy with anti-estrogens and anti-MUC-1 could be beneficial.

It was shown that most of the immunogenicity of MUC-1 resided in a repeated 20-aa peptide domain in the extracellular portion of the protein. This peptide, fused with oxidized mannan (M-FP) in an attempt to improve APC presentation, was able to induce both cytotoxic and humoral responses. ${ }^{87-90}$ Hence, a pilot Phase III study in early stage BC patients using oxidized mannan-MUC-1 was undertaken. ${ }^{91}$ In this small, placebo-controlled, randomized study, 31 patients with stage II and no more than four lymph nodes involved were injected with the vaccine after surgery, radiotherapy,

Table 3 Clinical trials with anti-HER2 vaccinations

\begin{tabular}{|c|c|c|c|c|}
\hline Platform & Vaccine & $\begin{array}{l}\text { Setting } \\
\text { and number } \\
\text { of patients }\end{array}$ & Adverse events & Results \\
\hline $\begin{array}{l}\text { Protein-based } \\
\text { vaccine }\end{array}$ & HER2 ICD + GM-CSF & Adjuvant, 29 pts & $\begin{array}{l}\text { No G2, G3, or G4 } \\
\text { toxicities reported }\end{array}$ & $\begin{array}{l}\text { Specific T-cell and antibody were elicited in } \\
89 \% \text { and } 82 \% \text { of pts, respectively }{ }^{70}\end{array}$ \\
\hline $\begin{array}{l}\text { Protein-based } \\
\text { vaccine }\end{array}$ & $\begin{array}{l}\text { dHER2 (truncated recombinant } \\
\text { HER2 ECD and ICD) }+ \\
\text { immunoadjuvant }\end{array}$ & Adjuvant, 45 pts & $\begin{array}{l}\text { One G3 fatigue } \\
\text { and one G3 } \\
\text { neutropenia }\end{array}$ & $\begin{array}{l}\text { HER2 ECD and ICD antibodies developed } \\
\text { after four immunizations } \\
\text { Two pts showed evidence of tumor regression }{ }^{72}\end{array}$ \\
\hline DNA-based vaccine & $\begin{array}{l}\text { Poxviral vector encoding } \\
\text { a modified form of the HER } 2 \\
\text { protein }\end{array}$ & Metastatic, 30 pts & $\begin{array}{l}\text { No G3 or G4 } \\
\text { toxicities reported }\end{array}$ & $\begin{array}{l}\text { HER2-specific antibodies and T-cell response } \\
\text { were detected in } 66 \% \text { pts ( } 15 \text { out of } 28 \text { ) } \\
\text { evaluable patients had SD after } 6 \text { months FU }\end{array}$ \\
\hline $\begin{array}{l}\text { Whole cell-based } \\
\text { vaccine }\end{array}$ & $\begin{array}{l}\text { SKBR3 (HER2 overexpressing } \\
\text { cell line) genetically modified } \\
\text { to secrete GM-CSF } \\
\text { administered with TReg } \\
\text { depleting doses of CY and DOX }\end{array}$ & Metastatic, 28 pts & $\begin{array}{l}\text { No } \mathrm{G} 3 \text { or } \mathrm{G} 4 \\
\text { toxicities reported }\end{array}$ & $\begin{array}{l}\text { Induction of efficient immune response, } \\
\text { including specific antibody production, } \\
\text { enhanced by } C Y \text { and } D O X^{73}\end{array}$ \\
\hline
\end{tabular}

Abbreviations: GM-CSF, granulocyte-macrophage colony-stimulating factor; ECD, extracellular domain; HER2, human epithelial growth factor receptor 2; ICD, intracellular domain; pts, patients; G, grade; BC, breast cancer; MBC, metastatic breast cancer; FU, follow-up; SD, stable disease;TReg, regulatoryT lymphocytes; CY, cyclophosphamide; DOX, doxorubicin; SKBR3, human HER2 overexpressing breast cancer cell line. 
and commencement of the adjuvant Tamoxifen. At 15 years of $\mathrm{FU}$, the recurrence rate in patients receiving placebo was $60 \%$ ( 9 out of 15 ), whereas in those receiving immunotherapy it was $12.5 \%$ ( 2 out of 16$)(P=0.002) .{ }^{92}$ All patients injected with M-FP showed no evidence of toxic effects or signs of autoimmunity during the 12-15-year FU. No response to MUC-1 was seen in the patients treated with placebo, whereas 9 of 13 patients immunized with MUC-1 had developed MUC-1-specific antibodies and 4 of 10 patients MUC-1specific T-cell responses. The clinical results obtained with this strategy are very promising, and further larger studies are warranted to confirm these results.

Carcinoembryonic antigen (CEA) is another glycoprotein aberrantly expressed in a multitude of cancer cell types, such as colorectal, lung, or breast cancer. ${ }^{93}$ It is a member of adhesion molecules, and its overexpression in cancer cells promotes their adhesion and the metastatic process. ${ }^{94}$ PANVACTM is a new cancer vaccine targeting both CEA and MUC-1. The vaccine is delivered through two sequential viral vectors, recombinant vaccinia $(\mathrm{rV}-)$ and recombinant fowlpox $(\mathrm{rF}-)$ - given in sequence, containing transgenes for the targets and for three human T-cell co-stimulatory molecules (TRICOM [TRIad of COstimulatory Molecules]) to enhance immune system activation. The PANVAC vaccines are injected subcutaneously and processed by APCs. ${ }^{95}$ In a pilot study, 26 heavily pretreated patients with ovarian cancer or BC were enrolled. Side effects were largely limited to mild injection-site reactions. For the 12 BC patients enrolled, the median time to progression was 2.5 months and the median OS was 13.7 months. One patient had a complete response and remained on study for 37 months and another had partial response, whereas four patients had stable disease. Patient with fewer previous lines of treatment or low tumor burden were more likely to respond to the vaccine. ${ }^{96}$ In another pilot study, 25 patients with advanced metastatic carcinoma were treated with the vaccine. Two patients with $\mathrm{BC}$ were enrolled, one had a confirmed decrease of $>20 \%$ in the size of large liver metastasis, whereas both had long-duration disease stabilization. ${ }^{97}$ These preliminary results show promising activity of this vaccine in BC, and further larger studies are currently going on.

\section{Anti-hTERT vaccines}

hTERT is another potential target for cancer vaccination. Telomerase is a ribonucleoprotein complex that maintains chromosomal integrity by protecting telomeric DNA for continuous cell proliferation. ${ }^{98}$ The complex contains hTERT and an RNA template. hTERT has broad expression in cancer cells, with little or no expression in normal somatic cells. A first pivotal study in 7 HLA-A2 advanced breast or prostate cancer patients showed good tolerability and promising clinical efficacy. Patients enrolled in this study were vaccinated with autologous monocyte-derived DCs pulsed ex vivo with hTERT I540 peptide and KLH as adjuvant. Among the two patients with $\mathrm{BC}$, one showed a mixed response of skin lesions, previously progressed despite chemo, hormonal, and radiotherapy. ${ }^{99}$ Another study was conducted on 19 HLA-A2positive patients with metastatic $\mathrm{BC}$ who were refractory to conventional therapy. Following vaccination, a specific CD8+ T-cell response was seen in more than $50 \%$ of the patients. Despite this, no objective responses were shown. However, in a post hoc analysis, it was shown that the median OS was significantly greater among patients with high CD8+ T-cell response than among low or no responders (32.2 months vs 17.5 months, $P=0.03) .{ }^{100}$

\section{Combining BC vaccines with other strategies}

Despite the encouraging preliminary results and excellent profile of tolerability, $\mathrm{BC}$ vaccines still show limited clinical efficacy. Antigen variability and mechanisms of tumor immune-escaping can impair the effectiveness of active immunization. Moreover, possible difficulties of the immune effectors to reach poorly vascularized tumors and high tumor burdens may contribute to limit the efficiency of vaccines. For patients with larger burdens of tumor and disseminated disease, it is fairly clear that vaccines alone are not able to outmatch the immune tolerance mechanisms of cancer cells; moreover, these become progressively more complex with tumor progression. Thus, a possible way to overcome the known limits of active immunotherapy may be combining $\mathrm{BC}$ vaccines with other strategies, such as systemic BC therapies, passive immunotherapy, or immunomodulatory agents. Interaction of $\mathrm{BC}$ vaccines and systemic therapy could be complex and poorly predictable. Thus, any combinatorial strategy requires strong biologic rationale. For example, target-immune checkpoints and reducing activity of T-Regs could overcome immune tolerance and increase the effectiveness of vaccination. Especially for patients with advanced disease, incorporating drugs that target BC-biology-inhibiting key intracellular signaling pathway may be required to enhance the activity of vaccines. In this field, results of first pivotal studies incorporating BC vaccines with targeted therapies have already been reported. Finally, disruption of tumor cells by conventional therapies could lead to the release of 
tumor fragments/antigens that are otherwise not accessible for presentation and processing and proinflammatory cytokines, with the final result of an increased immune response.

The humanized anti-HER2 monoclonal antibody trastuzumab has been combined with an HER2 peptide-based vaccine in a Phase I/II study in 22 pretreated patients with HER2 overexpressing stage IV BC. ${ }^{101}$ The association treatment was well tolerated and did not result in additional toxic effects. At a median FU of 36 months, the median progression free survival was 17.7 months (33\% proportion of patients without events at 3 years). This finding favorably compares with the results obtained in similar settings by conventional treatments.

Patil et $\mathrm{al}^{102}$ recently reported preliminary results of a Phase I study of trastuzumab in combination with GP2 vaccine plus GM-CSF in an adjuvant setting. Nineteen patients were treated. The combination was shown to be safe, with only mild reaction at the site of injection. No adverse cardiac events were reported. The vaccine was shown to be highly immunogenic, and further studies on this combination are warranted.

Trastuzumab has also been safely combined with an HER2-positive, GM-CSF-secreting, allogeneic breast tumor-cell vaccine. Twenty-two patients with HER2-positive metastatic BC were enrolled in this study. No dose-limiting toxic effects were observed. Clinical benefit rates (complete responses + partial responses + stable disease) at 6 and 12 months were 50\% (95\% CI, 27\%-72\%) and 35\% (95\% CI, 15\%-59\%), respectively. ${ }^{103}$

A plasmid DNA encoding HER-2/neu together with low doses of GM-CSF and IL-2 and concurrent trastuzumab has been tested in eight patients with metastatic HER2-positive BC. The study was conducted by Norell et al. ${ }^{104}$ No relevant toxic effects were observed. The treatment was shown to induce immediate and strong antibody production alongside long-lasting T-cell response. Notably, two out of six patients who completed all three vaccination cycles were long-term survivors, still alive more than 4 years after the last vaccination.

Finally, Hamilton et al ${ }^{105}$ published interesting results of a small pilot trial using recombinant anti-HER2 protein vaccine with concurrent Lapatinib in 12 women with trastuzumab-refractory HER2 overexpressing metastatic BC. No unexpected adverse events were shown. Specific anti-HER2 humoral response was induced in all patients. Interestingly, OS at 300 days was 92\% (95\% CI, $77 \%-100 \%)$.

\section{Conclusion and future perspectives}

In recent years, outstanding progress has been achieved toward the cure of $\mathrm{BC}$. More personalized therapies, molecularly targeted drugs, and a deeper understanding of the mechanisms of disease have allowed improving the prognosis of certain subtypes of tumor. In this rapidly changing scenario, there is a growing interest in developing an effective cancer vaccine. Unfortunately, none of the vaccine tested so far in clinical trials has turned out to be "practice changing." Nevertheless, three important lessons can be drawn.

First, many vaccines elicit a measurable immunologic response, such as specific antibodies or specific CD8+T-cells, but this response often has little or no impact on tumor growth. Engaging only one compartment of the immune system (eg, only cytotoxic response or humoral response) is probably not sufficient for an effective therapeutic vaccine. New vaccination strategies should therefore aim at eliciting a wide response, involving multiple immune effectors such as cytotoxic and antibody-secreting B-cells, innate immunity effectors, and memory cells. The underlying concept would be that a "complete" immunologic response may promote increased release of tumor cell fragments/antigens and proinflammatory cytokines, resulting in an immunologic virtuous cycle.

Second, the main barrier against vaccination is probably due to complex immuno-escaping mechanisms developed by cancer cells. Regulatory cells such as T-Regs and molecular immune checkpoints (eg, CTLA-4, PD1/PD1L) play crucial roles in maintaining self-tolerance, and tumors are able to exploit these elements to get protection from immune system's attack. New strategies based on blocking antibodies, recombinant forms of ligands, or receptors should be implemented to block such modulatory checkpoints and strengthen the immune response, with promising initial translation into clinical setting. One of the most intriguing perspectives of these strategies is obviously their synergism with immunotherapy approaches such as cancer vaccines.

Third, patients with large tumor burden and very advanced disease, enrolled in most of the clinical trials on cancer vaccines, are also those who benefit less from cancer vaccines alone. In fact, as cancer progresses and spreads in spite of multiple lines of treatment, immune-tolerance mechanisms become more intricate and the immune system is less likely to counteract the tumor. Therefore, in these patients, combining vaccine with established drugs targeting cancer biology, such as endocrine therapy, tyrosine receptor inhibitors, or chemotherapy, is required to achieve satisfactory 
clinical results. In conclusion, in order to maximize the likelihood of success, new BC vaccines should be developed by integrating a thorough understanding of immune tolerance mechanisms and tested in well-designed clinical trials conducted in immunologically favorable settings. Moreover, an additional effort should be made to improve immunotherapy in the specific basal-like subtype, which requires novel therapeutic strategies more than luminal and HER2-positive types.

\section{Acknowledgment}

This work has been funded by Grant GR-2009-1543842 and AIRC IG-2011 Grant no 11515.

\section{Disclosure}

The authors have no conflicts of interest to declare.

\section{References}

1. Winkfield KM, Harris JR. Effective local therapy and long-term survival in breast cancer. Oncology. 2009;23(8):669-675.

2. Siegel R, Naishadham D, Jemal A. Cancer statistics, 2013. CA Cancer J Clin. 2013;63(1):11-30.

3. Miles D, Roché H, Martin M, et al. Phase III multicenter clinical trial of the sialyl-TN (STn)-keyhole limpet hemocyanin $(\mathrm{KLH})$ vaccine for metastatic breast cancer. Oncologist. 2011;16(8):1092-1100.

4. Emens LA. Breast cancer immunobiology driving immunotherapy: vaccines and immune checkpoint blockade. Expert Rev Anticancer Ther. 2012;12(12):1597-1611.

5. Burnet FM. Immunological aspects of malignant disease. Lancet. 1967;1(7501):1171-1174

6. Shankaran V, Ikeda H, Bruce AT, et al. IFNgamma and lymphocytes prevent primary tumour development and shape tumour immunogenicity. Nature. 2001;410(6832):1107-1111.

7. Anderson KS. Tumor vaccines for breast cancer. Cancer Invest. 2009; 27(4):361-368.

8. Wilcox RA, Tamada K, Flies DB, et al. Ligation of CD137 receptor prevents and reverses established anergy of CD8+ cytolytic T lymphocytes in vivo. Blood. 2004;103(1):177-184.

9. Hakansson A, Gustafsson B, Krysander L, Hakansson L. Tumourinfiltrating lymphocytes in metastatic malignant melanoma and response to interferon alpha treatment. Br J Cancer. 1996;74(5):670-676.

10. Yasumoto K, Takeo S, Yano T, et al. Role of tumor-infiltrating lymphocytes in the host defense mechanism against lung cancer. J Surg Oncol. 1988;38(4):221-226.

11. Ravi R, Fuchs EJ, Jain A, et al. Resistance of cancers to immunologic cytotoxicity and adoptive immunotherapy via X-linked inhibitor of apoptosis protein expression and coexisting defects in mitochondrial death signaling. Cancer Res. 2006;66(3):1730-1739.

12. Zou W. Immunosuppressive networks in the tumour environment and their therapeutic relevance. Nat Rev Cancer. 2005;5(4):263-274.

13. Muschen M, Moers C, Warskulat U, Even J, Niederacher D, Beckmann MW. CD95 ligand expression as a mechanism of immune escape in breast cancer. Immunology. 2000;99(1):69-77.

14. Wolf AM, Wolf D, Steurer M, Gastl G, Gunsilius E, Grubeck-Loebenstein B. Increase of regulatory T-cells in the peripheral blood of cancer patients. Clin Cancer Res. 2003;9(2):606-612.

15. Riker A, Cormier J, Panelli M, et al. Immune selection after antigen-specific immunotherapy of melanoma. Surgery. 1999;126(2): $112-120$.
16. Marchini C, Kalogris C, Garulli C, et al. Tailoring DNA vaccines: designing strategies against HER2-positive cancers. Front Oncol. 2013;3:122.

17. Disis ML, Calenoff E, McLaughlin G, et al. Existent T-cell and antibody immunity to HER-2/neu protein in patients with breast cancer. Cancer Res. 1994;54(1):16-20.

18. Disis ML, Pupa SM, Gralow JR, Dittadi R, Menard S, Cheever MA. High-titer HER-2/neu protein-specific antibody can be detected in patients with early-stage breast cancer. J Clin Oncol. 1997;15(11): 3363-3367.

19. Miles D, Papazisis K. Rationale for the clinical development of STn$\mathrm{KLH}$ (Theratope) and anti-MUC-1 vaccines in breast cancer. Clin Breast Cancer. 2003;3(Suppl 4):S134-S138.

20. Hsieh CS, Lee HM, Lio CW. Selection of regulatory T cells in the thymus. Nat Rev Immunol. 2012;12(3):157-167.

21. Curigliano G, Criscitiello C, Esposito A, et al. Developing an effective breast cancer vaccine: challenges to achieving sterile immunity versus resetting equilibrium. Breast. 2013;22(Suppl 2):S96-S99.

22. Penwell A, Sharp K, Mansour M, Sammatur L. Development and validation of an HPLC/UV assay for separation and quantification of peptide antigens from a liposomal vaccine delivery platform. J Pharm Biomed Anal. 2012;66:176-182.

23. Marrache S, Tundup S, Harn DA, Dhar S. Ex vivo programming of dendritic cells by mitochondria-targeted nanoparticles to produce interferon-gamma for cancer immunotherapy. ACS Nano. 2013;7(8):7392-7402.

24. Pouyanfard S, Bamdad T, Hashemi H, Bandehpour M, Kazemi B. Induction of protective anti-CTL epitope responses against HER-2-positive breast cancer based on multivalent $\mathrm{T} 7$ phage nanoparticles. PLoS One. 2012;7(11):e49539.

25. Knutson KL, Schiffman K, Cheever MA, Disis ML. Immunization of cancer patients with a HER-2/neu, HLA-A2 peptide, p369-377, results in short-lived peptide-specific immunity. Clin Cancer Res. 2002;8(5): 1014-1018.

26. Knutson KL, Schiffman K, Disis ML. Immunization with a HER-2/neu helper peptide vaccine generates HER-2/neu CD8 T-cell immunity in cancer patients. J Clin Invest. 2001;107(4):477-484.

27. Zaks TZ, Rosenberg SA. Immunization with a peptide epitope (p369-377) from HER-2/neu leads to peptide-specific cytotoxic T lymphocytes that fail to recognize HER-2/neu+ tumors. Cancer Res. 1998;58(21): 4902-4908.

28. Mittendorf EA, Holmes JP, Murray JL, von Hofe E, Peoples GE. CD4+ $\mathrm{T}$ cells in antitumor immunity: utility of an li-key HER2/neu hybrid peptide vaccine (AE37). Expert Opin Biol Ther. 2009;9(1):71-78.

29. Pardoll DM, Topalian SL. The role of CD4+ T cell responses in antitumor immunity. Curr Opin Immunol. 1998;10(5):588-594.

30. Zwaveling S, Ferreira Mota SC, Nouta J, et al. Established human papillomavirus type 16-expressing tumors are effectively eradicated following vaccination with long peptides. J Immunol. 2002;169(1):350-358.

31. Milani A, Sangiolo D, Montemurro F, Aglietta M, Valabrega G. Active immunotherapy in HER2 overexpressing breast cancer: current status and future perspectives. Ann Oncol. 2013;24(7):1740-1748.

32. Gallo P, Dharmapuri S, Nuzzo M, et al. Xenogeneic immunization in mice using HER2 DNA delivered by an adenoviral vector. Int J Cancer. 2005;113(1):67-77.

33. Prud'homme GJ. DNA vaccination against tumors. J Gene Med. 2005; 7(1):3-17.

34. Hui KM, Ang PT, Huang L, Tay SK. Phase I study of immunotherapy of cutaneous metastases of human carcinoma using allogeneic and xenogeneic MHC DNA-liposome complexes. Gene Ther. 1997;4(8):783-790.

35. Pecher G, Spahn G, Schirrmann T, et al. Mucin gene (MUC1) transfer into human dendritic cells by cationic liposomes and recombinant adenovirus. Anticancer Res. 2001;21(4A):2591-2596.

36. Liu Z, Lv D, Liu S, et al. Alginic acid-coated chitosan nanoparticles loaded with legumain DNA vaccine: effect against breast cancer in mice. PLoS One. 2013;8(4):e60190. 
37. Curcio C, Di Carlo E, Clynes R, et al. Nonredundant roles of antibody, cytokines, and perforin in the eradication of established Her-2/neu carcinomas. J Clin Invest. 2003;111(8):1161-1170.

38. Spadaro M, Ambrosino E, Iezzi M, et al. Cure of mammary carcinomas in Her-2 transgenic mice through sequential stimulation of innate (neoadjuvant interleukin-12) and adaptive (DNA vaccine electroporation) immunity. Clin Cancer Res. 2005;11(5):1941-1952.

39. Rohrbach F, Weth R, Kursar M, Sloots A, Mittrucker HW, Wels WS. Targeted delivery of the ErbB2/HER2 tumor antigen to professional APCs results in effective antitumor immunity. J Immunol. 2005;174(9): 5481-5489.

40. Nabekura T, Nagasawa T, Nakauchi H, Onodera M. An immunotherapy approach with dendritic cells genetically modified to express the tumor-associated antigen, HER2. Cancer Immunol Immunother. 2008;57(5):611-622.

41. Zhang Y, Ma B, Zhou Y, et al. Dendritic cells fused with allogeneic breast cancer cell line induce tumor antigen-specific CTL responses against autologous breast cancer cells. Breast Cancer Res Treat. 2007;105(3):277-286.

42. Kantoff PW, Higano CS, Shore ND, et al. Sipuleucel-T immunotherapy for castration-resistant prostate cancer. $N$ Engl J Med. 2010;363(5):411-422.

43. Small EJ, Schellhammer PF, Higano CS, et al. Placebo-controlled Phase III trial of immunologic therapy with sipuleucel-T (APC8015) in patients with metastatic, asymptomatic hormone refractory prostate cancer. J Clin Oncol. 2006;24(19):3089-3094.

44. Rossi GR, Mautino MR, Awwad DZ, et al. Allogeneic melanoma vaccine expressing alphaGal epitopes induces antitumor immunity to autologous antigens in mice without signs of toxicity. $J$ Immunother 2008;31(6):545-554.

45. Keenan BP, Jaffee EM. Whole cell vaccines - past progress and future strategies. Semin Oncol. 2012;39(3):276-286.

46. Curigliano G, Spitaleri G, Pietri E, et al. Breast cancer vaccines: a clinical reality or fairy tale? Ann Oncol. 2006;17(5):750-762.

47. Slamon DJ, Godolphin W, Jones LA, et al. Studies of the HER-2/ neu proto-oncogene in human breast and ovarian cancer. Science. 1989;244(4905):707-712.

48. Slamon DJ, Leyland-Jones B, Shak S, et al. Use of chemotherapy plus a monoclonal antibody against HER2 for metastatic breast cancer that overexpresses HER2. N Engl J Med. 2001;344(11):783-792.

49. Baselga J, Cortes J, Kim SB, et al. Pertuzumab plus trastuzumab plus docetaxel for metastatic breast cancer. $N$ Engl J Med. 2012;366(2): 109-119.

50. Verma S, Miles D, Gianni L, et al. Trastuzumab emtansine for HER2-positive advanced breast cancer. N Engl J Med. 2012;367(19): 1783-1791.

51. Geyer CE, Forster J, Lindquist D, et al. Lapatinib plus capecitabine for HER2-positive advanced breast cancer. $N$ Engl J Med. 2006;355(26): 2733-2743.

52. Awada A, Dirix L, Manso Sanchez L, et al. Safety and efficacy of neratinib (HKI-272) plus vinorelbine in the treatment of patients with ErbB2-positive metastatic breast cancer pretreated with anti-HER2 therapy. Ann Oncol. 2013;24(1):109-116.

53. Geuna E, Montemurro F, Aglietta M, Valabrega G. Potential of afatinib in the treatment of patients with HER2-positive breast cancer. Breast Cancer. 2012;4:131-137.

54. Peoples GE, Goedegebuure PS, Smith R, Linehan DC, Yoshino I, Eberlein TJ. Breast and ovarian cancer-specific cytotoxic T lymphocytes recognize the same HER2/neu-derived peptide. Proc Natl Acad Sci USA. 1995;92(2):432-436

55. Fisk B, Blevins TL, Wharton JT, Ioannides CG. Identification of an immunodominant peptide of HER-2/neu protooncogene recognized by ovarian tumor-specific cytotoxic T lymphocyte lines. J Exp Med. 1995;181(6):2109-2117

56. Disis ML, Gooley TA, Rinn K, et al. Generation of T-cell immunity to the HER-2/neu protein after active immunization with HER-2/neu peptide-based vaccines. J Clin Oncol. 2002;20(11):2624-2632.
57. Murray JL, Gillogly ME, Przepiorka D, et al. Toxicity, immunogenicity, and induction of E75-specific tumor-lytic CTLs by HER-2 peptide E75 (369-377) combined with granulocyte macrophage colony-stimulating factor in HLA-A2+ patients with metastatic breast and ovarian cancer. Clin Cancer Res. 2002;8(11):3407-3418.

58. Salazar LG, Goodell V, O’Meara M, et al. Persistent immunity and survival after immunization with a HER2/neu (HER2) vaccine. ASCO Meeting Abstracts; 2009. Orlando, FL.

59. Peoples GE, Gurney JM, Hueman MT, et al. Clinical trial results of a HER2/neu (E75) vaccine to prevent recurrence in high-risk breast cancer patients. J Clin Oncol. 2005;23(30):7536-7545.

60. Peoples GE, Holmes JP, Hueman MT, et al. Combined clinical trial results of a HER2/neu (E75) vaccine for the prevention of recurrence in high-risk breast cancer patients: US Military Cancer Institute Clinical Trials Group Study I-01 and I-02. Clin Cancer Res. 2008;14(3): 797-803.

61. Mittendorf EA, Clifton GT, Holmes JP, et al. Final report of the Phase I/II clinical trial of the E75 (nelipepimut-S) vaccine with booster inoculations to prevent disease recurrence in high-risk breast cancer patients. Annals of Oncology. 2014;25(9):1735-1742.

62. Amin A, Benavides LC, Holmes JP, et al. Assessment of immunologic response and recurrence patterns among patients with clinical recurrence after vaccination with a preventive HER2/neu peptide vaccine: from US Military Cancer Institute Clinical Trials Group Study I-01 and I-02. Cancer Immunol Immunother. 2008;57(12):1817-1825.

63. Benavides LC, Gates JD, Carmichael MG, et al. The impact of HER2/ neu expression level on response to the E75 vaccine: from US Military Cancer Institute Clinical Trials Group Study I-01 and I-02. Clin Cancer Res. 2009;15(8):2895-2904.

64. Mittendorf EA, Clifton GT, Holmes JP, et al. Clinical trial results of the HER-2/neu (E75) vaccine to prevent breast cancer recurrence in high-risk patients: from US Military Cancer Institute Clinical Trials Group Study I-01 and I-02. Cancer. 2012;118(10):2594-2602.

65. Holmes JP, Benavides LC, Gates JD, et al. Results of the first Phase I clinical trial of the novel II-key hybrid preventive HER-2/neu peptide (AE37) vaccine. J Clin Oncol. 2008;26(20):3426-3433.

66. Hale DF, Perez SA, Vreeland TJ, et al. An assessment of disease features and immune response in breast cancer patients that did not recur after receiving HER2 peptide, AE37 vaccine in a randomized Phase II trial. ASCO Meeting Abstracts; 2012. Chicago, IL.

67. Anastasopoulou EA, Pappou E, Tzonis P, et al. Booster inoculations of the AE37 peptide vaccine enhance immunological responses in a Phase II study. ASCO Meeting Abstracts. 2013;31(Suppl 15):3095.

68. Carmichael MG, Benavides LC, Holmes JP, et al. Results of the first Phase 1 clinical trial of the HER-2/neu peptide (GP2) vaccine in diseasefree breast cancer patients: United States Military Cancer Institute Clinical Trials Group Study I-04. Cancer. 2010;116(2):292-301.

69. Trappey F, Berry JS, Vreeland TJ, et al. Randomized Phase II clinical trial of the anti-HER2 (GP2) vaccine to prevent recurrence in highrisk breast cancer patients: a planned interim analysis. ASCO Meeting Abstracts. 2013;31(Suppl 15):3005.

70. Disis ML, Schiffman K, Guthrie K, et al. Effect of dose on immune response in patients vaccinated with an her-2/neu intracellular domain protein - based vaccine. J Clin Oncol. 2004;22(10):1916-1925.

71. Guardino A, Cassidy M, Pienkowski T, et al. Results of two Phase I clinical trials of MVA-BN(R)-HER2 in HER-2 overexpressing metastatic breast cancer patients. Cancer Res. 2009;69(24):5089.

72. Limentani S, Dorval T, White S, et al. Phase I dose-escalation trial of a recombinant HER2 vaccine in patients with stage II/III HER2+ breast cancer. ASCO Meeting Abstracts; 2005. Chicago, IL.

73. Emens LA, Asquith JM, Leatherman JM, et al. Timed sequential treatment with cyclophosphamide, doxorubicin, and an allogeneic granulocyte-macrophage colony-stimulating factor-secreting breast tumor vaccine: a chemotherapy dose-ranging factorial study of safety and immune activation. J Clin Oncol. 2009;27(35):5911-5918.

74. Yang E, Hu XF, Xing PX. Advances of MUC1 as a target for breast cancer immunotherapy. Histol Histopathol. 2007;22(8):905-922. 
75. Tarp MA, Clausen H. Mucin-type O-glycosylation and its potential use in drug and vaccine development. Biochim Biophys Acta. 2008;1780(3): 546-563.

76. Apostolopoulos V, Xing PX, McKenzie IF. Murine immune response to cells transfected with human MUC1: immunization with cellular and synthetic antigens. Cancer Res. 1994;54(19):5186-5193.

77. Zhang S, Graeber LA, Helling F, et al. Augmenting the immunogenicity of synthetic MUC1 peptide vaccines in mice. Cancer Res. 1996;56(14):3315-3319.

78. Acres RB, Hareuveni M, Balloul JM, Kieny MP. Vaccinia virus MUC1 immunization of mice: immune response and protection against the growth of murine tumors bearing the MUC1 antigen. $J$ Immunother Emphasis Tumor Immunol. 1993;14(2):136-143.

79. Goydos JS, Elder E, Whiteside TL, Finn OJ, Lotze MT. A Phase I trial of a synthetic mucin peptide vaccine. Induction of specific immune reactivity in patients with adenocarcinoma. $J$ Surg Res. 1996;63(1): 298-304.

80. Ramanathan RK, Lee KM, McKolanis J, et al. Phase I study of a MUC1 vaccine composed of different doses of MUC1 peptide with SB-AS2 adjuvant in resected and locally advanced pancreatic cancer. Cancer Immunol Immunother. 2005;54(3):254-264.

81. Adluri S, Gilewski T, Zhang S, Ramnath V, Ragupathi G, Livingston P. Specificity analysis of sera from breast cancer patients vaccinated with MUC1-KLH plus QS-21. Br J Cancer. 1999;79(11-12):1806-1812.

82. Gilewski T, Adluri S, Ragupathi G, et al. Vaccination of high-risk breast cancer patients with mucin-1 (MUC1) keyhole limpet hemocyanin conjugate plus QS-21. Clin Cancer Res. 2000;6(5):1693-1701.

83. Palmer M, Parker J, Modi S, et al. Phase I study of the BLP25 (MUC1 peptide) liposomal vaccine for active specific immunotherapy in stage IIIB/IV non-small-cell lung cancer. Clin Lung Cancer. 2001;3(1):49-57; discussion 58.

84. MacLean GD, Reddish M, Koganty RR, et al. Immunization of breast cancer patients using a synthetic sialyl-Tn glycoconjugate plus Detox adjuvant. Cancer Immunol Immunother. 1993;36(4):215-222.

85. Reddish MA, MacLean GD, Poppema S, Berg A, Longenecker BM. Pre-immunotherapy serum CA27.29 (MUC-1) mucin level and CD69+ lymphocytes correlate with effects of Theratope sialyl-Tn-KLH cancer vaccine in active specific immunotherapy. Cancer Immunol Immunother. 1996;42(5):303-309.

86. Miles DW, Towlson KE, Graham R, et al. A randomised Phase II study of sialyl-Tn and DETOX-B adjuvant with or without cyclophosphamide pretreatment for the active specific immunotherapy of breast cancer. $\mathrm{Br}$ J Cancer. 1996;74(8):1292-1296.

87. Xing P, Michael M, Apostolopoulos V, et al. Phase-I study of synthetic muc1 peptides in breast-cancer. Int J Oncol. 1995;6(6):1283-1289.

88. Karanikas V, Hwang LA, Pearson J, et al. Antibody and T cell responses of patients with adenocarcinoma immunized with mannan-MUC1 fusion protein. J Clin Invest. 1997;100(11):2783-2792.

89. Karanikas V, Lodding J, Maino VC, McKenzie IF. Flow cytometric measurement of intracellular cytokines detects immune responses in MUC1 immunotherapy. Clin Cancer Res. 2000;6(3):829-837.

90. Karanikas V, Thynne G, Mitchell P, et al. Mannan mucin-1 peptide immunization: influence of cyclophosphamide and the route of injection. J Immunother. 2001;24(2):172-183.
91. Apostolopoulos V, Pietersz GA, Tsibanis A, et al. Pilot Phase III immunotherapy study in early-stage breast cancer patients using oxidized mannan-MUC1 [ISRCTN71711835]. Breast Cancer Res. 2006;8(3):R27.

92. Vassilaros S, Tsibanis A, Tsikkinis A, Pietersz GA, McKenzie IF, Apostolopoulos V. Up to 15-year clinical follow-up of a pilot Phase III immunotherapy study in stage II breast cancer patients using oxidized mannan-MUC1. Immunotherapy. 2013;5(11):1177-1182.

93. Turriziani M, Fantini M, Benvenuto M, et al. Carcinoembryonic antigen (CEA)-based cancer vaccines: recent patents and antitumor effects from experimental models to clinical trials. Recent Pat Anticancer Drug Discov. 2012;7(3):265-296.

94. Curigliano G, Rescigno M, Goldhirsch A. Immunology and breast cancer: therapeutic cancer vaccines. Breast. 2007;16(Suppl 2):S20-S26.

95. Madan RA, Arlen PM, Gulley JL. PANVAC-VF: poxviral-based vaccine therapy targeting CEA and MUC1 in carcinoma. Expert Opin Biol Ther. 2007;7(4):543-554

96. Mohebtash M, Tsang KY, Madan RA, et al. A pilot study of MUC-1/ CEA/TRICOM poxviral-based vaccine in patients with metastatic breast and ovarian cancer. Clin Cancer Res. 2011;17(22):7164-7173.

97. Gulley JL, Arlen PM, Tsang KY, et al. Pilot study of vaccination with recombinant CEA-MUC-1-TRICOM poxviral-based vaccines in patients with metastatic carcinoma. Clin Cancer Res. 2008;14(10):3060-3069.

98. Coveler AL, Bates NE, Disis ML. Progress in the development of a therapeutic vaccine for breast cancer. Breast Cancer. 2010;2:25-36.

99. Vonderheide RH, Domchek SM, Schultze JL, et al. Vaccination of cancer patients against telomerase induces functional antitumor CD8+ T lymphocytes. Clin Cancer Res. 2004;10(3):828-839.

100. Domchek SM, Recio A, Mick R, et al. Telomerase-specific T-cell immunity in breast cancer: effect of vaccination on tumor immunosurveillance. Cancer Res. 2007;67(21):10546-10555.

101. Disis ML, Wallace DR, Gooley TA, et al. Concurrent trastuzumab and HER2/neu-specific vaccination in patients with metastatic breast cancer. J Clin Oncol. 2009;27(28):4685-4692.

102. Patil R, Clifton GT, Litton JK, et al. Safety and efficacy of the HER2derived GP2 peptide vaccine in combination with trastuzumab for breast cancer patients in the adjuvant setting. ASCO Meeting Abstracts. 2013;31(Suppl 15):3096.

103. Emens LA, Gupta R, Petrik S, et al. A feasibility study of combination therapy with trastuzumab (T), cyclophosphamide (CY), and an allogeneic GM-CSF-secreting breast tumor vaccine for the treatment of HER2+ metastatic breast cancer. ASCO Meeting Abstracts; 2011. Chicago, IL.

104. Norell H, Poschke I, Charo J, et al. Vaccination with a plasmid DNA encoding HER-2/neu together with low doses of GM-CSF and IL-2 in patients with metastatic breast carcinoma: a pilot clinical trial. J Transl Med. 2010;8:53.

105. Hamilton E, Blackwell K, Hobeika AC, et al. Phase I clinical trial of HER2-specific immunotherapy with concomitant HER2 kinase inhibition. J Transl Med. 2012;10:28.
Breast Cancer: Targets and Therapy

\section{Publish your work in this journal}

Breast Cancer: Targets and Therapy is an international, peerreviewed open access journal focusing on breast cancer research, identification of therapeutic targets and the optimal use of preventative and integrated treatment interventions to achieve improved outcomes, enhanced survival and quality of life for the cancer patient.

\section{Dovepress}

View the full aims and scopes of this journal here. The manuscript management system is completely online and includes a very quick and fair peer-review system, which is all easy to use. Visit http:// www.dovepress.com/testimonials.php to read real quotes from published authors. 